\title{
A metrópole para além da nação: globalização e crise urbana
}

\author{
The metropolis beyond the nation: \\ globalization and urban crisis
}

Maurilio Lima Botelho [I]

\begin{abstract}
Resumo
0 objetivo deste artigo, mais precisamente um ensaio, é refletir sobre o papel das grandes cidades e metrópoles numa economia global, enfatizando a contradição entre a concentração de riquezas e o desemprego crescente nessas aglomerações urbanas. Enfocamos o significado da emergência das cidades globais, cujo nível de integração social e econômica transfronteiriça, que supera as escalas tradicionais, significa uma implosão da economia nacional. Destacamos que as características das metrópoles atuais precisam ser refletidas como parte de uma crise urbana global.
\end{abstract}

Palavras-chave: metrópoles; cidades globais; desemprego; globalização; crise urbana.

\begin{abstract}
The aim of this article - more precisely, an essay - is to reflect on the role of large cities and metropolises in a global economy, emphasizing the contradiction between concentration of wealth and increasing unemployment in these urban agglomerations. We focus on the significance of the emerging global cities, whose level of cross-border social and economic integration, which surpasses traditional scales, means an implosion of the domestic economy. We highlight that the characteristics of current metropolises have to be viewed as part of a global urban crisis.
\end{abstract}

Keywords: metropolises; global cities; unemployment; globalization; urban crisis. 
A consultoria inglesa Oxford Economics, especializada em estudos econômicos e assessoria ao mercado financeiro, analisou o desenvolvimento das maiores cidades do mundo, projetando o crescimento para o ano de 2030. 0 objetivo era avaliar as tendências de mercado em cidades de todo o planeta. Tendo por base os dados de 2013 e acompanhando o seu presumido crescimento, a consultoria chegou a um resultado que não é exatamente original, mas desperta reflexões por enfatizar a concentração de riquezas nas principais metrópoles mundiais: em 2030, as 750 maiores aglomerações urbanas do mundo terão $35 \%$ da população mundial (2,8 bilhões de habitantes) e serão responsáveis por $61 \%$ do PIB mundial ( 80 trilhões de dólares) (Oxford Economics, 2018, p. 2).

Interessados principalmente em informações como o incremento no consumo nessas localidades (mais 18 trilhões de dólares nesse período), o envelhecimento populacional (um acréscimo de 15 milhões de idosos), a demanda por escritórios (540 milhões de metros quadrados) e uma necessidade de criação de 240 milhões de empregos, os consultores da Oxford Economics, economistas em sua maioria, preocupavam-se em formular estratégias empresariais para explorar essas "oportunidades". Entretanto, no meio dessas projeções, há elementos que, além de dar conta da concentração de renda, também apontam para problemas graves a serem enfrentados por esse universo urbano hipertrofiado.

Em 2030, segundo essas projeções, as 750 maiores concentrações urbanas terão ampliado sua participação no PIB mundial em cerca de $7 \%$, enquanto a população, nesse período, terá aumentado pouco mais de $5 \%$.
Portanto, além de apresentar quase o dobro da riqueza em proporção à população, esse conjunto das maiores cidades do mundo deve ampliar ainda mais sua fatia na renda mundial. Compostos principalmente por grandes regiões metropolitanas (São Paulo, Paris, Moscou), algumas megalópoles (Tóquio) e até mesmo por megacidades (Lagos, Kinshasa e Mumbai), os tecidos urbanos gigantescos são muito diversos e, por isso, também apresentam concentração de renda ainda mais expressiva entre eles (ibid.).

Cerca de um quarto de todo o incremento em riqueza no período de 2012-2030 será concentrado em apenas 20 das maiores cidades. Ou seja, 8,7 trilhões de dólares a mais no PIB das cidades mais ricas do mundo. Isso revela um drama nessas imensas máquinas urbanas de produção de riqueza, pois, mesmo com a industrialização assustadora das cidades chinesas, a expansão econômica na Índia e uma presença cada vez maior de centros urbanos do Oriente Médio e América Latina nas primeiras posições, permanece uma forte concentração da riqueza nas economias centrais. ${ }^{1}$ Nos termos facilmente criticáveis da projeção estatística, o cidadão médio de Pequim deverá levar ainda 24 anos para atingir o padrão de consumo comparável ao de Nova York (mantidas as taxas de crescimento atuais). Um morador de Nova Déli, por sua vez, levará 50 anos para chegar a esse mesmo padrão. Lagos, uma das cidades de fratura social mais grave em todo 0 mundo hoje, terá que percorrer 150 anos para atingir esse nível de consumo (ibid., p. 4).

É evidente que esse desdobramento do padrão de consumo em termos temporais não serve em nada para antecipar o futuro dessas cidades - presta apenas para uma indicação da 
brutal diferença do nível de vida hoje. Ao projetar esse tipo de variável na história futura, os economistas estão pressupondo a manutenção de um ritmo atual de crescimento econômico que é insustentável. ${ }^{2}$

0 estudo da Oxford Economics até ressalta o desafio que será a geração de empregos para países africanos cuja população tende a crescer vertiginosamente nos próximos anos, particularmente a população jovem que pressionará o mercado de trabalho. Entretanto, tudo isso é visto como uma "dádiva" (gift), na medida em que representa incremento de população economicamente ativa. Parte-se aqui de outra preconcepção altamente questionável: a de que, inevitavelmente, a expansão econômica deve promover a criação de empregos. Um dos principais índices do relatório The Global Cities 2030 não estimula uma reflexão sobre esse tema em seus próprios autores: em 2030, as 750 maiores cidades do mundo terão $30 \%$ dos empregos do planeta, um índice proporcionalmente inferior à população que apresentarão (35\%), assim como muito abaixo da riqueza mundial nelas concentrada (61\%). Isto é um indício claro de que, no capitalismo avançado, a produção econômica não é necessariamente acompanhada de uma criação de oportunidades de trabalho: há uma desconexão cada vez maior entre produção e trabalho. Mais ainda: como a riqueza tende a se concentrar, há um grau elevado de exclusão social, mesmo em meio a cidades globais de alta renda. Por último, é preciso ressaltar que, diferentemente de um passado em que o êxodo rural-urbano representava quase sempre elevação do nível de vida para os indivíduos implicados, o processo de "urbanização planetária", hoje, significa desafios incalculáveis para os novos moradores das cidades: não apenas o problema de desemprego e informalidade crescente ou a violência e militarização dos espaços urbanos, mas principalmente uma exposição a problemas ambientais que só agora começam a ser tematizados.

Nosso objetivo, neste artigo, é refletir sobre alguns desses aspectos a seguir, principalmente a relação entre produção de riqueza e o desemprego nas metrópoles (seção 1), a exclusão social crescente nas cidades globais e seus impactos sobre as suas respectivas economias nacionais (seção 2). Por fim, discutimos rapidamente a própria concepção atual de metrópole a partir da reflexão realizada.

\section{0 desemprego nas metrópoles: desconexão entre produção e trabalho}

A evidente desproporção entre a riqueza produzida nas cidades e a oferta de postos de trabalho aí presentes foi captada pela projeção da Oxford Economics. Estamos diante de uma incomum condição em que algumas das principais cidades do mundo, as mais ricas do ponto de vista de acúmulo e produção de riquezas, apresentam taxas de desemprego acima da média de suas respectivas economias nacionais.

No Brasil, essa situação é evidente, hoje, com as metrópoles mais ricas do País apresentando taxas de desocupação acima da média nacional. Assim, as regiões metropolitanas de Belo Horizonte, Brasília, Rio de Janeiro e São Paulo apresentaram taxas respectivas de desocupação de $15,4 \%, 13,1 \%, 14,9 \%$ e $14,6 \%$, 
diante de uma média de $12,7 \%$ no País em 2017. ${ }^{3}$ Esses números ainda são pouco expressivos porque muitas dessas cidades, particularmente o caso do Rio de Janeiro, têm um elevado nível de informalidade, o que significa que o desemprego é apenas um dos sintomas de pobreza e exclusão social. Isso é ainda mais atual porque a maior parte da população economicamente ativa nacional já está em condição informal (sem carteira assinada ou como "trabalhador por conta própria"). ${ }^{4}$ Ainda concentrando boa parte da produção industrial do País e grande parcela das atividades financeiras, as metrópoles mais dinâmicas apresentam um número de excluídos do mercado de trabalho mais amplo, sinal de uma dissociação entre produção de riqueza e oportunidades de emprego.

No resto do mundo, a situação repete-se nas grandes aglomerações urbanas de diversos e importantes países. Em 2016, a França fechou o ano com uma taxa de desemprego nacional de $9,5 \%$, mas sua capital, autêntica cidade global por seus atributos culturais, políticos e financeiros, possuía uma taxa de $12 \%$. Entretanto, esse índice esconde a profundidade da pobreza e da exclusão: a desocupação entre jovens é gigantesca e, entre a população de imigrantes ou seus descendentes, as taxas saltam. A comuna de Clichy-sous-Bois, parte do Departamento do Sena, um subúrbio principalmente de imigrantes na metrópole parisiense, tem $40 \%$ de jovens sem emprego. ${ }^{5}$ Isso cria uma constante tensão política e social: não é um acaso que essa localidade tenha sido um dos epicentros das grandes revoltas dos banlieus em 2005.

Na Alemanha, o principal "motor econômico" da Europa e cuja economia parece, aos olhos do mundo, sempre inabalada, também reproduz essa discrepância entre índices nacionais e escassez de emprego em seus centros urbanos. Em 2017, o país apresentou uma taxa oficial de desemprego baixíssima para seus padrões nas últimas décadas - atingiu 5,7\% na média nacional. Entretanto, mesmo desconsiderando que as metodologias constantemente renovadas estejam reduzindo a capacidade de aferir a real exclusão do mercado de trabalho, ${ }^{6}$ essa taxa de desemprego começa a ter tons cinzentos quando se observam as maiores cidades, conforme explica Zeuner, da KfW.

0 mercado de trabalho alemão está muito desequilibrado, com fortes diferenças em função das regiões e setores. Enquanto na Baviera ou em Baden-Württemberg podemos falar de pleno emprego, com uma taxa de cerca de $3 \%$ (as cidades-estados) de Berlim e Bremen ainda estão longe, com taxas de 8 ou $10 \%{ }^{7}$

Na Alemanha, como no Brasil, a taxa de desemprego esconde um aspecto muito mais problemático que são as variadas formas de subocupação e empregos precários cuja função tem sido a de garantir minimante a sobrevivência:

A precariedade em que vivem muitos trabalhadores é, porém, o lado sombrio do modelo alemão, apresentado por vezes como exemplo. Trabalho barato, minijobs, trabalho em part-time e temporário [...] Essas formas de trabalho ocupavam, em 2012, oito milhões de alemães. ${ }^{8}$

0 mesmo ocorre no estado mais rico do mundo: a Califórnia, nos EUA, normalmente apontada como uma das dez maiores economias do mundo se avaliada isoladamente. 
Envolvendo cidades como São Francisco, Los Angeles e San Diego, boa parte do estado poderia ser tomada como uma única megalópole (nomeada como SanSan pelos limites norte e sul). Aí se concentra o núcleo do complexo industrial-militar nos EUA, assim como o principal polo de tecnologia microeletrônica do mundo (Vale do Silício). Entretanto, há alguns anos (2012), a Califórnia apresentava uma taxa de desemprego de 10,5\%, enquanto a média nacional era de 8,3\%. Suas metrópoles expressavam um drama ainda maior: sete das oito regiões metropolitanas dos EUA com taxas de desemprego acima de 15\% estavam no estado da Califórnia. Esse quadro assustador possuía uma síntese em Los Angeles, a capital do estado e centro de uma região metropolitana com mais de 10 milhões de pessoas e 88 municípios:

Demolidoras são as conclusões do relatório "A Time for Truth", elaborado pela Los Angeles 2020 Comission, uma comissão independente formada por 13 cidadãos e presidida pelo ex-Secretário de Comércio, Mickey Kantor.

"Los Angeles mal se move, quando o resto do mundo marcha para diante. Estamos falhando em nos adaptar às realidades do século XXI e estamos nos convertendo em uma cidade em declive". Assim começa 0 relatório, e continua com um devastador olhar para o que considera as marcas "do que um dia foi o lugar onde acontecia 0 futuro e agora vive no passado".

A primeira dessas marcas é a pobreza, com $40 \%$ da população vivendo na miséria, uma percentagem que é a mais alta entre as grandes cidades dos EUA. Segundo o relatório, isso é produto de "duas décadas de lento crescimento do emprego, com taxas de desemprego muito acima das do resto da nação, e do congelamento dos salários, com $28 \%$ dos trabalhadores que não recebem um valor suficiente para viver". ${ }^{9}$

É verdade que a situação parece ter amenizado nos EUA nos anos posteriores à publicação desse relatório citado, mas, longe de representar uma melhoria social amparada em crescimento econômico, as taxas decrescentes de desemprego são muito mais o resultado de uma crescente informalização (tendência mundial), da desistência na busca por emprego (o desalento comum a quem enfrenta o desemprego de longo prazo) e uma nova bolha financeira que ameaça romper a qualquer momento. Os dramáticos relatos do economista Lewis (2011) sobre os efeitos da explosão da bolha imobiliária de 2007/2008 nas municipalidades californianas - com paralisia de serviços públicos, demissão massiva de membros da polícia e bombeiros, bibliotecas fechando e expansão da miséria - ameaça se repetir e se agravar.

Cidades do cinturão do Sol, Paris, Berlim, Rio de Janeiro e São Paulo - os exemplos poderiam ser multiplicados e indicam uma desconexão progressiva entre a produção de riqueza nas metrópoles mais ricas do mundo em relação à oferta de trabalho. Trata-se de uma tendência inerente ao capitalismo em uma era de crise estrutural (Botelho, 2018). 0 declínio acentuado do capitalismo tem como um dos seus pressupostos a progressiva exclusão da força de trabalho dos processos produtivos, resultado das transformações tecnológicas recentes, que estão transitando da Terceira Revolução Industrial (energia nuclear, microeletrônica, biotecnologia) para uma Quarta Revolução (inteligência artificial, nanotecnologia, bioengenharia). 
Mais importante do que um registro dos impactos econômicos da revolução tecnológica sobre o mercado de trabalho, é importante ressaltar a ruptura interna provocada na economia de mercado pelas inovações dos últimos 50 anos. Não temos apenas um mero "desemprego tecnológico", de manifestação temporária, decorrente da aplicação das renovações técnicas aos processos produtivos. A revolução microeletrônica provocou uma dissociação entre o ritmo de crescimento da economia e a geração de empregos, ou seja, a velocidade de racionalização dos processos de produção não é mais acompanhada por uma expansão dos mercados. Esse fenômeno foi observado já na década de 1970, exatamente quando o ciclo de expansão econômica global do pós-guerra se esgotou:

Em contraste direto com o desenvolvimento nos anos 50 e ainda nos anos 60 , nos anos 70 as taxas de crescimento da produtividade do trabalho estão acima das da produção - com a consequência de que a força de trabalho liberada pelo progresso técnico não mais pode ser absorvida pela expansão da produção. (Offe, 1989, p. 92)

Assim, se no seio da produção capitalista temos um contraste entre a produção de mercadorias e a diminuição de empregos (jobless growth), nos centros urbanos mais importantes do mundo há uma contradição crescente entre acumulação de riquezas e desemprego. As maiores cidades mundiais, as metrópoles mais ricas e, particularmente, as cidades globais são a vanguarda de um processo em que a força de trabalho se torna progressivamente descartável, na mesma proporção em que as riquezas se acumulam em poucas mãos e locais. ${ }^{10}$

\section{As cidades globais: desconexão entre as capitais da riqueza e a economia nacional}

Na conhecida definição do grupo de pesquisas GaWC - Globalization and World Cities, que reúne principalmente pesquisadores da Universidade de Loughborough, no Reino Unido, uma cidade global (cidade mundial, na tradução literal) é um centro urbano com importância e influência global determinada, entre outras características, pela existência de uma bolsa de valores de grande magnitude financeira, com sedes de grandes corporações multinacionais, sistema aeroportuário amplo, setor sofisticado de serviços e escritórios, centro de tecnologia avançada e museus de referência.

Os pesquisadores do GaWC hierarquizam as cidades globais a partir dessas características. Entre as cidades que se destacam pela atuação de empresas líderes mundiais em finanças, contabilidade, propaganda, direito e administração estão Londres, Nova York, Hong Kong, Paris, Tóquio, Singapura, Shanghai, Pequim, Sidnei e Dubai. Muitas outras cidades também aparecem, mas têm posições periféricas de acordo com a classificação (Taylor, 2018). Como se vê, o critério de divisão mundial entre centro e periferia não tem prioridade sobre a hierarquização das cidades globais: entre as dez maiores cidades do ponto de vista corporativo, cinco pelo menos estão fora do tradicional Primeiro Mundo (Hong Kong, Singapura, Shanghai, Pequim e Dubai).

Esse é um importante registro que nos aproxima de uma das principais faces da relação contemporânea entre economia e as cidades globais: a desconexão do tecido urbano 
local com a economia nacional. Um dos efeitos dessa ruptura é a emergência de grandes centros urbanos, com importância crescente na arena internacional, em países que persistem com uma brutal desigualdade de renda, miséria e problemas sociais básicos. Entretanto, isso não é apenas uma tendência de polarização social emergente no tradicional Terceiro Mundo, pois grandes metrópoles do mundo desenvolvido dissociam cada vez mais sua ascensão econômica do restante de seu território nacional.

A autora que melhor identificou essa característica absolutamente central das chamadas cidades globais foi Saskia Sassen. Mais do que uma consequência, essas cidades são fundamentais no processo de globalização:

À medida que a economia global se expandiu nas duas últimas décadas, assistimos à formação de uma rede crescente de cidades globais, hoje somando em torno de 40 , pelas quais a riqueza econômica e os processos nacionais se articulam com uma proliferação de circuitos globais de capital, investimento e comércio. Essa rede de cidades globais constitui um espaço de poder que contém as capacidades necessárias para as operações globais de empresas e mercados. Ela atravessa parcialmente a velha divisão Norte-Sul e constitui uma geografia de centralidade, que atualmente também incorpora as principais cidades do Sul global, ainda que a hierarquia dessa geografia de centralidade seja bastante nítida. Em seu nível mais concreto, essa nova geografia é o terreno em que diversos processos da globalização assumem formas materiais e localizadas. Uma análise das cidades globais e suas redes nos ajuda a entender como a centralidade espacial e organizacional é institucionalizada na economia global. (Sassen, 2010, p. 24)
Entretanto, essas cidades, partes ainda ativas na integração global de mercados cada vez mais restritivos, aproveitam-se de uma condição tecnológica e econômica de ligação direta que rompe com a linearidade de escalas (local, regional, nacional, global). As cidades globais mobilizam fluxos transnacionais que ultrapassam as tradicionais hierarquias que compreendiam os antigos Estados-Nações.

A cidade, aqui, não é uma unidade limitada, mas uma estrutura complexa que pode articular uma variedade de processos transfronteiriços e reconstituí-los como uma condição parcialmente urbana. Além disso, esse tipo de cidade não pode ser simplesmente localizado em uma hierarquia escalar que o coloca abaixo do nacional, do regional e do global. Ele é um dos espaços do global, e o aciona diretamente, muitas vezes passando por cima do nacional. Algumas cidades talvez tenham tido essa capacidade muito antes da era atual, mas, hoje em dia, essas condições se multiplicam e amplificam, até 0 ponto em que podem ser lidas como algo que contribui para uma era urbana qualitativamente diferente. (Ibid., p. 89)

Um traço importante dessa oportunidade criada pelas condições tecnológicas superdesenvolvidas (microeletrônica, rede de informações globais, mercados financeiros conectados em tempo real, etc.) é que as localidades mais pujantes, do ponto de vista da produção de riqueza, podem se conectar sem precisar da intermediação de uma hinterlândia empobrecida ou descartável. Não vivemos apenas uma competição entre cidades globais (embora isso seja cada vez mais uma pressão mundial dos investidores para a atração de investimentos), mas também uma colaboração direta entre 
essas aglomerações urbanas, pois a economia capitalista hoje necessita de uma infraestrutura global em pontos de conexão privilegiados. ${ }^{11}$

$\mathrm{Na}$ verdade, até mesmo o conceito de polo de crescimento, com sua região, hinterlândia ou uma área de influência polarizada por esse núcleo, precisa ser rediscutido (Perroux, 1975). Sem dúvida que a concentração de investimentos, de riqueza e de oportunidades nas grandes metrópoles cria uma força de atração sobre o território ao seu redor. Mas é a desconexão territorial que precisa ser refletida hoje com as cidades globais: essa desconexão se manifesta na relação com o interior da própria metrópole e, sobretudo, na sua relação com o território nacional.

Primeiro, como resultado de uma profunda mudança de época, isto é, de declínio da capacidade de criação de empregos da produção capitalista, a concentração de investimentos nas cidades globais não representa necessariamente geração de riqueza para todos, mas quase sempre uma concentração de renda que se manifesta por meio de uma ampliação de desemprego e, principalmente, por uma expressiva segmentação do mercado de trabalho entre atividades econômicas avançadas e serviços secundários que dissolvem a antiga classe trabalhadora.

Assim, o que temos é principalmente uma cidade partida entre uma minoria integrada aos circuitos globais da produção das riquezas capitalistas, enquanto um exército de empregos ocupados por mulheres e migrantes, sub-remunerados, ou um grande conjunto de atividades informais, como a prestação de serviços alimentares, limpeza, transporte e prostituição formam a maioria do mercado de trabalho, sem contar aí os descartados pela economia capitalista cada vez mais restritiva. Mais complexo do que o próprio problema do desemprego aberto, como registrado acima, são as zonas cinzentas de uma precarização cada vez mais profunda.

No Brasil, devido à proliferação de atividades econômicas por conta própria, "bicos", informalidade, etc., sempre foi difícil determinar precisamente as fronteiras entre a "ocupação" e a "desocupação": "o mercado de trabalho não demarca, ao menos com a clareza que seria analiticamente esperada, as fronteiras que separam a 'atividade econômica' (para o que 'ocupação' e 'desemprego' se constituem nas situações alternativas típicas) da 'inatividade econômica'" (Guimarães e Araújo, 2006, p. 168). Se há algumas décadas isso poderia ser qualificado como algo típico do Brasil ou da periferia do capitalismo, agora essa se torna uma norma quase universal:

[...] as fronteiras entre trabalho e desocupação se tornam fluídas. Generalizam-se formas plurais, flexíveis, de subemprego. Inclusive no último recanto social se faz patente que a norma do pleno emprego para toda a vida está sendo substituída por múltiplas formas de flexibilizações de tempo de trabalho. Menos conhecido é que isto poderia valer, em um futuro próximo, também para o caso da concentração espacial e também para a "organização produtiva" do trabalho. (Beck, 1998, p. 178)

Além disso, uma segunda desconexão territorial manifesta-se de modo ainda mais gritante com a emergência de cidades globais. A capacidade de integração transfronteiriça e transnacional permite às cidades globais passarem por cima das regiões nacionais supérfluas para as novas necessidades de uma 
economia capitalista em crise. A competição entre cidades, que seleciona e projeta poucas aglomerações à escala mundial, é também uma seleção que desdenha e exclui a maioria dos outros centros urbanos nacionais - o privilégio corporativo, financeiro e político a um número reduzido de cidades que concentram investimentos, infraestrutura e renda.

Ao mesmo tempo, existe um aumento da desigualdade na concentração de atividades e recursos estratégicos em cada uma dessas cidades, em comparação com outras cidades nos mesmos países. Ao lado dessas novas redes globais e regionais de cidades, existe um vasto território que está se tornando cada vez mais periférico e cada vez mais excluído dos principais processos econômicos que alimentam 0 crescimento econômico global. Antigos centros industriais e cidades portuárias importantes perderam funções ou encontram-se em declínio, não apenas nos países menos desenvolvidos, mas também nas economias mais avançadas. De maneira semelhante, na avaliação das formas de mão de obra, a supervalorização de serviços especializados e trabalhadores profissionais tem marcado muitos dos "outros" tipos de atividades econômicas e trabalhadores como desnecessários ou irrelevantes para a economia avançada. (Sassen, 2010, p. 96)

Ainda que tenhamos notado a concentração de renda em poucas metrópoles do mundo e principalmente nos países centrais, já estamos além de uma condição em que apenas cidades do capitalismo periférico apresentam aquela fratura social em que dois circuitos de produção e consumo se manifestam na paisagem urbana (Santos, 1979). 0 que já foi apontado como uma "brasilianização do mundo" (Beck, 1998) corresponde à emergência dessa contradição que se manifesta tanto no espaço nacional quanto no próprio espaço intraurbano: a ampliação de riquezas manifesta-se em um mercado de trabalho urbano fragmentado e na vertiginosa exclusão social, por um lado, assim como na dissociação entre a economia urbana e a economia regional ou nacional, por outro.

Estamos no limite de uma formação urbana que não respeita as fronteiras nacionais e, pelo contrário, explora exatamente as oportunidades geradas pela conexão tecnofinanceira mundial, em detrimento de qualquer perspectiva de desenvolvimento nacional. A supressão da linearidade e hierarquia entre escalas não é apenas uma reconfiguração geográfica nacional ou mundial - como se estivéssemos no umbral de uma nova conformação espacial diante da qual bastaria ajustar a sociedade, a política e o Estado para desenvolver suas potencialidades. 0 que se trata aqui é da própria inviabilidade do desenvolvimento nacional, pois a alta tecnologia e a concentração de investimentos caminham passo a passo com a miséria absurda e a precariedade urbana mais chocante.

o Primeiro e o Terceiro Mundo estão em todos os lugares. Em Gelsenkirchen encontramos o Primeiro Mundo ao lado do Terceiro Mundo; na Bulgária e na Índia encontramos produtores de softwares competitivos, o Brasil exporta com êxito aviões militares e produtos químicos sem falar do sudeste asiático -, mas logo ao lado começa a favela. Este é um mundo que segue o princípio da "autossemeIhança", como poderíamos definir quase ironicamente, conforme o princípio da Teoria do Caos. As microestruturas correspondem à macroestrutura, existindo as assim chamadas ilhas de produtividade 
em cada cidade, cada bairro, cada país, em breve, em cada região do mundo, que sempre ainda podem produzir para o mercado mundial - e ao lado a favelização. (Kurz, 2004, pp. 29-30)

Não enfrentamos mais uma polarização crescente em escala nacional, mas a própria implosão do caráter nacional dos territórios. Não é casual que, entre os principais critérios para a entrada no seleto rol das cidades globais, estejam aeroportos internacionais, bolsas de valores de grande mobilização de capital, escritórios sofisticados com conexão telemática e museus de referência mundial. 0 atributo principal de cada uma dessas infraestruturas é a sua utilidade para uma elite global que já não tem nenhum vínculo imediato com qualquer sociedade nacional ou mesmo com comunidades locais. Os fundos imobiliários no Rio de Janeiro estão recebendo investimentos canadenses e sauditas; os teatros de São Paulo recebem óperas italianas para um público que será formado parcialmente por empresários estrangeiros; o aeroporto da Cidade do México possui voo para Dubai; prédios inteligentes em Johanesburgo possuem conexão de vídeo em alta velocidade com Nova York ou Londres e parte dessa elite mundial se reúne anualmente em Davos. ${ }^{12}$ Enfim, a oferta desses serviços urbanos é menos uma "oportunidade aberta" para o desenvolvimento nacional e mais a criação de nichos excludentes de mercado em que os "olímpicos" da sociedade global se movimentam indiferentes aos problemas mais básicos que se avolumam com a crise do capital. ${ }^{13}$

Para um número crescente de pessoas, nossas nações e o sistema do qual eles fazem parte agora parecem incapazes de oferecer um futuro viável e plausível.
Esse é particularmente o caso quando eles observam as elites financeiras - e sua riqueza - escaparem cada vez mais de lealdades nacionais. 0 fracasso atual da autoridade política nacional, afinal, deriva em grande parte da perda de controle sobre os fluxos de dinheiro. No nível mais óbvio, o dinheiro está sendo transferido do espaço nacional para uma zona offshore em expansão. Esses trilhões em fuga prejudicam as comunidades nacionais de maneira real e simbólica. Eles são uma causa de decadência nacional, mas também são um resultado: os estados-nação perderam sua aura moral, que é uma das razões pelas quais a evasão fiscal se tornou um fundamento aceito do comércio do século XXI. (Dasgupta, 2018)

Isso é muito mais do que um exagero retórico. 0 capital sempre se movimentou internacionalmente e criou elites que circularam pelo mundo como senhores do destino de suas nações e de outros países, como aprendemos desde o domínio colonial. Entretanto, há algo absolutamente novo que não se restringe ao fluxo de capital monetário, embora sua predominância crescente sobre a produção industrial e, principalmente, sua capacidade ilusória de multiplicar-se independentemente das condições econômicas reais (capital fictício) sejam o fundamento dessa nova realidade crítica. 0 que temos é uma desintegração nacional que se arrasta pelo mundo e envolve tanto a alta mobilidade do capital quanto a regressão a um fundamentalismo religioso apátrida; inclui a ideologia econômica neoliberal radical reproduzida por todos os espectros políticos (direita ou esquerda) e a fragmentação político-partidária; incorpora o endividamento insustentável dos Estados e a crescente demanda por políticas assistenciais da maioria das populações 
desempregadas ou precarizadas. ${ }^{14}$ Enfim, visto de um patamar mais amplo, mesmo com sua massa de desempregados e subempregados, as cidades globais são ilhas de prosperidade num mundo cada vez mais estilhaçado por mudanças geológicas que arrastam as estruturas sociais tradicionais para um abismo de tensão, violência aberta e guerra civil.

as estruturas políticas do século XX estão se afogando em um oceano de finanças desregulamentadas, tecnologia autônoma, militância religiosa e rivalidade de grandes potências do século XXI. Enquanto isso, as consequências reprimidas da imprudência do século 20 no mundo outrora colonizado estão em erupção, fragmentando nações e forçando as populações a solidariedades pós-nacionais: milícias tribais itinerantes, subestados étnicos e religiosos e superestados. Finalmente, a demolição das antigas superpotências da sociedade internacional - ideias da "sociedade das nações" que eram essenciais para a maneira como a nova ordem mundial era imaginada depois de 1918 transformou o sistema de Estado-nação em uma terra de gangues [gangland] sem lei; e isso está produzindo agora uma reação niilista daqueles que foram mais aterrorizados e despojados. (Dasgupta, 2018)

Movimentos contrários a imigrantes, escalada militar de potências regionais ou mesmo a reativação de protecionismo econômico (Trump), por meio dos quais se dá a aparente era de retorno ao nacionalismo, não são elementos que negam essa desintegração nacional, mas a demonstração exata de sua força que, por ser tão avassaladora, provoca resistências e respostas contraditórias. Aliás, é significativo que as formas "pós-políticas" em ascensão estejam cada vez mais centradas na escala urbana propriamente dita do que no território nacional. Os grupos mafiosos e milicianos que buscam controle territorial o fazem principalmente em bairros e cidades onde possam cultivar um mercado de venda de proteção, extorsão e comércio irregular (desde drogas até produtos de alta tecnologia contrabandeados). 0 rápido sucesso do Estado Islâmico (agora sob forte redução com a intervenção russa na Guerra da Síria) foi obtido exatamente pela construção de uma rede urbana de domínio que ignorava as fronteiras nacionais no Oriente Médio e que impunha a sharia como forma de legitimação. Em muitos "estados falhados" da África, os grupos terroristas e guerrilheiros, as milícias e as facções do crime controlam um conjunto de centros urbanos de um território estilhaçado e, não raro, disputam uma mesma grande cidade para tentar impor seu domínio sobre os demais "grupos insurgentes". Por fim, a própria administração urbana, numa economia conectada por meio de fluxos financeiros extremamente voláteis, tende a ser "pós-nacional".

As reflexões de Castells e Borja (1996) sobre as cidades como "atores políticos" internacionais realizaram-se num sentido negativo: tendo seus prefeitos e alcaides elevados à condição de "promotores de eventos", a função primordial dos grandes centros urbanos é criar um ambiente de negócios prioritário aos investimentos, e, por isso, seus administradores muitas vezes saltam as escalas regionais e nacionais para negociar em âmbito internacional. Como argumentou precisamente Smith (2001), hoje as cidades estão erigindo suas próprias "políticas externas" e, por essa razão, rompendo as escalas tradicionais da organização política e social. Beck também citou os efeitos de espaços sociais transnacionais que levam cada 
vez mais prefeitos de cidades mexicanas a Nova York para tratar de "projetos de desenvolvimento local" (1999, pp. 62-63). No caso do Rio de Janeiro dos "megaeventos", isso se tornou mais simbólico do que em qualquer outro lugar, com o prefeito pessoalmente convidando ou contratando celebridades internacionais, diretores de cinema e arquitetos-artistas para atuarem na (temporária) centralidade emergente da "Cidade Maravilhosa".

0 mais significativo é que essas duas faces não são excludentes, pelo contrário, alimentam-se mutuamente: a mesma municipalidade que ainda mantém o status de cidade global (ou que almeja esse posto, como foi o caso do Rio de Janeiro) em geral precisa responder aos problemas de uma estrutura política e social em desintegração, ou seja, precisa demonstrar capacidade de contenção dos grupos mafiosos, milicianos e da violência fora dos bairros turísticos e das zonas centrais de negócios. 0 forte controle policial do espaço urbano e a militarização direta das cidades tornam-se uma necessidade insubstituível para administrar as tensões crescentes, mesmo no seio das cidades globais. Nova York, com sua "tolerância zero"; a repressão às periferias em chamas de Paris; a violenta resposta ao terrorismo ou a potenciais "suspeitos" em Londres são apenas versões distintas da mesma "pacificação" levada em curso no Rio de Janeiro, ainda que aqui a magnitude do problema seja muito mais grave pelas condições históricas de fratura social. 0 "novo urbanismo militar" é a maneira como as grandes cidades respondem às ameaças a sua estrutura política.
[...] não é de se surpreender que as cidades centrais e periféricas comecem a parecer-se: fronteiras fortemente militarizadas, cercas, guardas ao redor de enclaves ou "zonas de segurança", células de identidades, videocâmeras computadorizadas, vigilância biométrica e controles de acesso militarizados ao redor de centros sociais e econômicos fortificados contra uma massa ingovernável e perigosa. Nos mais extremos exemplos, a ideia de prisões militares e os enclaves étnicos agora crescem ao redor dos distritos financeiros, as embaixadas, os espaços de turismo e consumo dos aeroportos, as arenas desportivas, as comunidades "exclusivas" e as zonas de exportação". (Graham, 2012, p. 15)

Poderíamos falar até mesmo de uma outra desconexão em curso: no mesmo sentido de uma cidade que já não apresenta mais a capacidade ampla de inclusão econômica, também a forma urbana de um capitalismo em crise se manifesta como uma exclusão social e jurídica crescente. 0 velho lema do "ar da cidade liberta", se nunca foi além de um ideologema da forma social burguesa em ascensão, agora está muito longe de qualquer materialização - para evitar a queda na conflagração social e violência generalizada, as cidades integradas aos circuitos globais precisam cada vez mais corresponder a espaços de controle, no quais seus cidadãos são monitorados na mesma medida em que os excluídos (não cidadãos) precisam ser confinados (nas prisões, nos guetos, nas favelas, atrás de muros, etc.). ${ }^{15}$ 


\section{Conclusões}

Os dados mais recentes mostram a impressionante explosão da pobreza em São Paulo: em apenas um ano, a pobreza extrema cresceu $35 \% .{ }^{16}$ Assim, ao lado dos bairros elitizados e de alta renda, como Morumbi, Jardins e Alto de Pinheiros, temos favelas gigantescas e imensas periferias nas quais a vida é garantida todo dia por meio de empregos precários e de informalidade, sob a vigilância de leis não escritas do PCC (Primeiro Comando da Capital).

Na Índia, na megacidade de Mumbai, cujos limites urbanos explodiram num vertiginoso crescimento nas últimas décadas, a população total já ultrapassa 20 milhões em sua área metropolitana. Conhecida mundialmente pela pobreza, falta de saneamento e precariedade na infraestrutura, a partir da década de 1970 a administração pública indiana construiu uma estrutura urbana totalmente nova para acomodar as grandes corporações nacionais e multinacionais, os serviços modernos (redes de fast food e restaurantes de grife) e as sedes burocráticas estatais. A nova cidade no continente, chamada de Navi Mumbai, sintetiza a segregação urbana quando confrontada às ilhas que compõem a velha cidade: "tornou-se especializada em alta tecnologia, que emprega pouco e obrigou milhares de operários de sua construção a retornar à superpovoada Mumbai" (Nunomura, 2008).

Em Nova York, naquela que é considerada ainda a capital mundial do capitalismo, cidade com o maior número de bilionários no mundo, a desigualdade social também salta aos olhos: mais de 70 mil pessoas vivem nas ruas, tendo que apelar aos abrigos em noites mais frias. Do outro lado do país, na capital do estado mais rico do planeta, há também 58 mil pessoas sem tetos:

Nos Estados Unidos, há 553.000 pessoas sem moradia segundo o último censo do Departamento de Habitação publicado no início de dezembro. Corresponde a $0,17 \%$ da população, uma porcentagem superior ao México $(0,04 \%)$, mas inferior ao Canadá $(0,44 \%)$, Reino Unido $(0,25 \%)$ e Suécia $(0,36 \%)$, segundo dados compilados pela OCDE. Um em cada cinco vive em Nova York ou em Los Angeles. Em números absolutos, a cidade de Nova York é a que mais tem sem-tetos nos EUA, acima de 76.000. A diferença é que, em Nova York, 90\% têm onde passar a noite. Três em cada quatro pessoas sem teto em Los Angeles não têm cama em algum albergue ou solução temporária. (Número de moradores..., 2017) ${ }^{17}$

Essa ampliação generalizada dos sem-tetos nos Estados Unidos indica que os mais recentes índices de euforia econômica e redução de desemprego são muito frágeis e mais dependentes de simulação financeira do que propriamente de um crescimento sustentado.

Na Europa, a situação não é distinta. Na capital da França, o número de sem-tetos é baixo, mas a gravidade se deve ao modo como se acentuou: em dez anos, o número de pessoas sem domicílio fixo aumentou em $50 \%$, o que deixa cerca de 3 mil pessoas nas ruas (Em 10 anos... (2017). Até um problema aparentemente restrito ao chamado Terceiro Mundo começou a se manifestar aí: em 2105, a polícia fez uma grande operação para remover a maior favela de Paris, com mais de 400 pessoas. Cada vez mais em terrenos baldios, estradas de ferro abandonadas e prédios desativados surgem 
favelas pela França, principalmente na região metropolitana de Paris. Em todo o país já são mais de 500 bidonvilles, como são intituladas (Favelas em Paris..., 2017).

Em Londres, o problema dos sem-tetos é ainda mais assustador: há em torno de 144 mil desabrigados pelas ruas da metrópole britânica ("Discharged to the streets"..., 2018). Londres não costuma aparecer na lista das metrópoles com taxas de desemprego acima da média nacional. A prosperidade da capital parece evitar esse problema. Entretanto, a grande vitalidade da cidade, que é a sede do maior mercado financeiro do mundo (em número de negociações), já foi explicada pela extrema concentração de riquezas em relação ao resto do país. Doreen Massey, em obra dedicada à análise de Londres como uma "cidade mundial", apontou exatamente como a sede da City conseguiu superar a decadência econômica das décadas de 1970-1980, especializando-se em serviços financeiros. Isso levou a uma extrema concentração de renda e a uma polarização social entre a cidade e o resto do país, assim como implicou aumento dos custos de vida na capital e gigantesca alta imobiliária, o que criou moradias cada vez mais precárias para trabalhadores de baixa renda, informais e desempregados.

A concentração espacial da economia e sociedade em um canto do Reino Unido, e especialmente dentro da Inglaterra, é um fato centenário. Mas nas décadas recentes tem aumentado sua intensidade. A natureza das relações que mantêm unida essa geografia tem mudado e se concentrado mais. Cada vez mais o país está sendo levado a um vórtice, centrado nas finanças e nos serviços financeiros em expansão, que conformam a infraestrutura cultural do neoliberalismo junto com um setor imobiliário que mantêm e se beneficia de seu crescimento. Isto é tanto uma revisão como um reforço dos aspectos de uma larga divisão nacional espacial do trabalho e, de novo, claramente articulada, dependente e um dos nós de criação da economia internacional. (Massey, 2008, pp. 178-179)

Ou seja, a resposta britânica à evidente decadência nacional nas últimas décadas do século XXI - marcada sobretudo pela desindustrialização - foi uma ênfase no caráter de cidade global de sua capital, o que pode ser lido como uma outra forma de capitulação e abandono da economia nacional.

Essas breves radiografias do contraste urbano espalhado pelo mundo dão conta de uma realidade que já não é mais específica da periferia do capitalismo. Se "o terceiro mundo está contido no primeiro" (Beck, 1999, p. 111), isso se deve às mudanças profundas na economia capitalista que atingiu o seu limite histórico de desenvolvimento (Botelho, 2018).

Tornou-se um lugar comum afirmar que as grandes cidades, as metrópoles e, particularmente, as chamadas cidades globais são os locais onde emergem de modo mais nítido os conflitos e as contradições do processo de globalização. Entretanto, essa afirmação, para ter um significado mais profundo do que o de uma mera frase retórica ou redundante (cidades globais são, evidentemente, expressões de um processo que tensiona o local e o global), precisa ser determinada pelo contexto de crise do capitalismo.

Em certo sentido, a definição mais precisa da metrópole, hoje, deveria conter exatamente esse caráter crítico, que envolve a irradiação e a fragmentação do tecido urbano, 
cuja dinâmica ultrapassa fronteiras e, por isso, integra "redes" que se destacam por explorar ainda as áreas oportunas para a acumulação monetária, enquanto outras são relegadas à sobrevivência por sua própria sorte. No conceito de metrópole atual, baseado num espaço abstrato amplificado ao extremo pela lógica da mercadoria, é preciso ter em conta o caráter da própria crise dessa forma de mediação social: a simultânea existência do urbano como um "local" e uma "rede" em que as dimensões regionais e nacionais são abandonadas pela rentabilidade levada ao extremo. ${ }^{18}$

Temos um paradoxo em que, quanto mais amplas as cidades e mais urbanizadas as regiões - a ponto de a ONU empregar agora categorias como "cidades-regiões" ou "corredores urbanos" (2010, p. 4) -, mais descontínuos e fragmentados social e economicamente estão esses espaços, em boa parte social e racialmente segregados.

Mais do que uma "nova era" e para além da emergência de uma condição urbana original que deve exigir a geração de novos instrumentos teóricos, a integração global de determinadas centralidades urbanas deve ser vista como parte do processo de crise estrutural da economia capitalista. "A crise agora é mais urbana do que nunca" (Harvey, 2014, p. 112). Isso significa, sem dúvida, que a teoria deve captar novas dinâmicas sociais, mas que não pode facilmente se render a esses processos como se fossem estáveis, como se indicassem o surgimento de um "novo ciclo" ou sequer como novas configurações políticas globais. 0 processo de globalização é ao mesmo tempo uma causa e um resultado da crise do capital, que se tornou, pela primeira vez na sua história, capital global (Botelho, 2018, pp. 172-176). As metrópoles, portanto, não apresentam hoje dinâmicas que exprimem meramente uma mudança de época, mas, sobretudo, o declínio de uma era que não pode mais retornar. Além disso, mais do que um palco onde esses processos se desenrolam, as metrópoles e as cidades globais são formas urbanas complexas que demonstram ativamente como a dinâmica se dirige à insustentabilidade econômica e social (para não dizer também ambiental). Assim, as grandes áreas urbanas do mundo são hoje as principais estruturas que impulsionam o processo de globalização em direção a tensões graves e destrutivas.

\section{[I] https://orcid.org/0000-0001-5807-262X}

Universidade Federal Rural do Rio de Janeiro, Departamento de Geografia. Rio de Janeiro, RJ/Brasil. mauriliolimabotelho@gmail.com 


\section{Notas}

(1) Um relatório mais antigo da consultoria inglesa PricewaterhouseCoopers também apontava uma crescente importância das aglomerações urbanas da periferia do capitalismo entre as maiores do mundo, mas a concentração de riquezas entre as cidades globais teria pouca redução. No ranking das 100 cidades com maiores PIBs do mundo, apenas o G7 teria, em 2025, 36 cidades, enquanto todas as "economias emergentes" teriam 48 aglomerações urbanas. Em 2008, essa relação estava entre 41 e 39 cidades, respectivamente $(2009$, p. 25).

(2) Tendo por base os preços e os dados de 2012, o estudo segue um padrão de crescimento econômico que não se sustenta, por exemplo, para a economia chinesa, que teve uma desaceleração brutal em seu crescimento econômico nos últimos anos. O mesmo poderia ser dito em relação a outros "países emergentes" que colapsaram com a explosão da "bolha das commodities". O estudo concentra sua projeção de crescimento do PIB nas aglomerações urbanas periféricas entre taxas de crescimento que vão de 4 a 10\% (Oxford Economics, 2018, p. 6). Essa observação vale, ainda, para a projeção realizada pela PricewaterhouseCoopers no relatório UK Economic Outlook, que partia de taxas de crescimento bastante elevadas para as economias emergentes. Como apontou um dos responsáveis pelo estudo: "Cidades como Xangai, Pequim e Mumbai, por exemplo, estão projetadas para crescer em torno de 6 a $7 \%$ ao ano em termos reais, enquanto cidades como Nova York, Tóquio, Chicago e Londres crescem apenas cerca de 2\% ao ano" (Emerging..., 2009)..

(3) Esses números são da PNAD Contínua do IBGE do quarto trimestre de 2017, compreendendo as médias desse ano. Disponível em: https://ww2.ibge.gov.br/home/estatistica/ indicadores/ trabalhoerendimento/pnad_continua/default_comentarios_sinteticos.shtm. Acesso em: maio 2017.

(4) No Brasil, ao fim de 2017, temos 34,31 milhões de pessoas "por conta própria" ou sem carteira, quase um milhão acima dos 33,32 milhões ocupados em vagas de empregos formais. (Trabalho sem carteira assinada e "por conta própria" supera pela primeira vez emprego formal em 2017, aponta IBGE, G1, 31 jan 2018. Disponível em: https://g1.globo.com/economia/noticia/trabalhosem-carteira-assinada-e-por-conta-propria-supera-pela-1-vez-emprego-formal-em-2017aponta-ibge.ghtml. Acesso em: abr 2018). Se acrescentarmos o fato de que, após a reforma trabalhista e a lei de terceirização, há uma tendência para a troca de empregados formais por informais, o quadro torna-se ainda mais dramático.

(5) Subúrbio de Paris tem vista privilegiada, mas desemprego evidencia décadas de fracassos, 0 Globo, 18 mar 2016. Disponível em: https://oglobo.globo.com/economia/suburbio-de-paristem-vista-privilegiada-mas-desemprego-evidencia-decadas-de-fracassos-15642242. Acesso em: maio 2018.

(6) Taxa de desemprego na Alemanha é manipulada, Deutsche Welle, 4 jan. 2018. Disponível em: http:// www.dw.com/pt-br/taxa-de-desemprego-na-alemanha-\%C3\%A9-manipulada/a-42014674. Acesso em: maio 2018. Robert Kurz já havia alertado para a prática de "truques" para esconder os dados alarmantes de desemprego, algo não restrito à Alemanha: "Essa maquiagem do desemprego em massa com ajuda de truques estatísticos é comum em todos os países que ainda se utilizam de estatísticas de desemprego. Na República Federal da Alemanha, essa maquiagem pode ser vista pela mudança na apresentação do índice que, até alguns anos atrás, ainda era feita em relação ao número total de empregados, isto é, de assalariados. Entrementes, já se faz a relação com o número total da população economicamente ativa, incluindo todos 
os autônomos, os empresários e a força de trabalho de família integrada para embelezar a estatística. Estes são apenas exemplos; os truques mudam de estado para estado, de país para país, mas são aplicados" (Kurz, 2004, pp. 17-18).

(7) Desemprego na Alemanha fecha 2017 com 5,7\%, mínimo recorde, AFP, 3 jan. 2018. Disponível em: http://anoticia.clicrbs.com.br/sc/mundo/noticia/2018/01/desemprego-na-alemanhafecha-2017-com-5-7-minimo-recorde-10109631.html. Acesso em: abr 2018.

(8) O lado sombrio da baixa taxa de desemprego alemã, Diário de Notícias, 21 set 2013. Disponível em: https://www.dn.pt/dossiers/mundo/eleicoes-na-alemanha-2013/noticias/interior/o-ladosombrio-da-baixa-taxa-de-desemprego-alema-3432474.html\#. Acesso em: abr 2018.

(9) Los Angeles, uma cidade em declive, El Pais, 10 jan 2014. Disponível em: https://brasil.elpais. com/brasil/2014/01/08/internacional/1389219779_971330.html. Acesso em: maio 2018.

(10) "[...] o desemprego em massa começa a lançar uma sombra realmente ameaçadora, não somente sobre a vida socioeconômica de um ou outro país, mas sobre todo o sistema do capital. Pois uma coisa é imaginar o alívio ou a remoção do impacto negativo do desemprego em massa de um, ou mesmo mais de um, país particular mediante a transferência de sua carga para alguma outra parte do mundo, ao 'melhorar a posição competitiva' do país ou dos países em questão: um remédio tradicional nos textos, de que até hoje se ouve falar. Entretanto, outra coisa completamente diferente é sonhar com essa solução quando a doença afeta todo o sistema, estabelecendo um limite óbvio ao que um país pode fazer para 'mendigar ao vizinho', ou mesmo o resto do mundo, caso se trate do país hegemônico mais poderoso, caso dos Estados Unidos no período posterior à Segunda Guerra Mundial. Sob essas circunstâncias, ativa-se a 'explosão populacional', sob a forma de desemprego crônico, como um limite absoluto do capital” (Mészáros, 2002, p. 333).

(11) “[...] as cidades globais não apenas competem entre si. Juntas elas proporcionam uma infraestrutura em rede crítica para a gestão e o controle de cadeias globais de transações, cada uma com considerável especificidade de funções. O resultado se dá nas múltiplas divisões do trabalho entre cidades, contribuindo para articulações características da economia global que vão além da articulação centro-periferia" (Sassen, 2010, pp. 58-59).

(12) "Apesar de diferenças em seus lugares de origem, a multidão de Davos tem hoje mais em comum uns com os outros do que com aqueles que não vivem naquela altitude rarefeita. Um antigo alto funcionário do governo americano confirmou essa observação: 'Acho que o que está acontecendo tem a ver com a própria identidade pessoal deles', me disse ele. 'Eles têm uma ligação maior com Davos e sua espécie do que com as pessoas em casa'. [...] Sempre houve ligações entre as elites de diferentes países, mas elas eram tipicamente 'relações exteriores' ligações entre centros de poder distantes, alianças discretas entre soberanos. Porém, há várias décadas tem se formado uma nova comunidade, ao mesmo tempo que as economias cruzam fronteiras, instituições globais se proliferam e o mundo está, bem, ficando plano" (Rothkopf, 2008, pp. 31-32).

(13) "Lefebvre fala, em sua sociologia crítica, dos segmentos privilegiados da moderna sociedade de consumo como os novos 'olímpicos'. O termo refere-se ao modo como as elites se colocam acima das contradições do cotidiano vivido pela maioria dos habitantes 'comuns'” (Barreira, 2013, p. 159). 
(14) E, na medida em que a produção de riquezas perde sua base nacional, o endividamento estatal se aprofunda para lidar com as consequências desse desenraizamento: "o desenvolvimento econômico escapa ao controle do Estado nacional, enquanto as suas consequências desemprego, emigração, pobreza - se acumulam nas redes de captação do Estado do bem-estar social" (Beck, 1998, p. 36). Isso significa dizer que os críticos das teorias sobre a globalização têm uma certa razão em dizer que o Estado passa a ter funções cada vez mais importantes, mas foram retiradas as condições econômicas de exercer essas tarefas cada vez mais emergenciais do ponto de vista da reprodução social. Não é um acaso que o welfare state se converta num warfare state, em que se declara guerra aos pobres e excluídos.

(15) "Essa desproporcionalidade do desenvolvimento urbano pautado por diferenças sociais de classe constitui, de fato, um problema global. Vem ocorrendo atualmente na Índia, assim como nas inumeráveis cidades ao redor do mundo onde há concentrações emergentes de populações marginalizadas, ao lado de uma urbanização moderníssima e consumista voltada para uma minoria cada vez mais rica. A questão de como lidar com os trabalhadores empobrecidos, precários e excluídos, que hoje constituem um bloco de poder majoritário e supostamente dominante em muitas cidades, está se transformando em um grande problema político. Em decorrência disso, o planejamento militar está extremamente focado em lidar com os movimentos de base urbana, irrequietos e potencialmente revolucionários" (Harvey, 2014, p. 129). A ênfase "revolucionária" fica por conta da leitura de Harvey do período em que escrevia o texto, quando movimentos urbanos em várias partes do mundo pareciam indicar um ressurgimento das lutas sociais. Não é possível manter esse otimismo para os desdobramentos da crise urbana mundial, ainda mais uma esperança de que esses movimentos fossem indícios de uma "revolução urbana".

(16) “Maior polo de riqueza do país, a região metropolitana de São Paulo, que concentra 39 municípios, tem 700.193 pessoas vivendo na pobreza extrema, número 35\% maior do que era em 2016. São 180 mil pessoas a mais, mostra análise da LCA Consultores a partir de dados recentemente divulgados pelo Instituto Brasileiro de Geografia e Estatística"(Na Grande SP..., 2018).

(17) Uma reportagem recente dá conta de mais de 100 mil sem-tetos no estado da Califórnia (Com mais de 100 mil..., 2018).

(18) A definição de metrópole de Cunningham (2010) vai exatamente nesse sentido, embora negligencie o aspecto de crise que há nesse processo de abrangência global da forma urbana: "[...] na medida em que o conceito de metrópole como forma pura já se apresenta em relação a um horizonte projetado da equivalência absoluta, ele não parece redundante no que se refere a um conhecimento adequado da forma urbana contemporânea. Se assim for, pode agora aparecer de duas maneiras diferentes (mas inter-relacionadas): por um lado, como os 'elementos dispersos de uma rede global interconectada - uma rede que é constitutiva da forma particular e da 'experiência' de qualquer metrópole particular - e, por outro, como a forma básica e generalizada da própria rede, que é, portanto, conceitualmente moldada como uma espécie de 'metrópole virtual' (para tomar emprestada uma frase de Koolhaas), historicamente nova e universalmente 'irradiada'. Talvez o jogo recíproco entre esses diferentes níveis e suas formas 'quase lógicas' possa definir conceitualmente a problemática urbana contemporânea mundial. No mínimo, parece ser possível argumentar que a metrópole ainda se apresenta, de modo produtivo, como a mutação de uma 'figura hegemônica' - um ponto de mediação com as formas mais gerais de experiência social e prática - conceitualmente homóloga às tendências gerais de desenvolvimento do capitalismo urbano global". 


\section{Referências}

BARREIRA, M. (2013). "Cidade Olímpica: sobre o nexo entre reestruturação urbana e violência na cidade do Rio de Janeiro". In: BRITO, F. e OLIVEIRA, P. R. de (orgs.). Até o último homem: visões cariocas da administração armada da vida social. São Paulo, Boitempo.

BECK, U. (1998). La sociedad del riesgo. Hacia uma nova modernidade. Barcelona, Paidós.

(1999). O que é globalização? Equívocos do globalismo. Respostas à globalização. São Paulo, Paz e Terra.

BOTELHO, M. L. (2018). Entre as crises e o colapso: cinco notas sobre a falência estrutural do capitalismo. Revista Maracanan, n. 18, pp. 157-180.

CASTELLS, M. e BORJA, J. (1996). As cidades como atores políticos. Novos Estudos CEBRAP, n. 45, pp. 152-166.

COM MAIS DE 100 MIL moradores de rua, Califórnia não encontra onde abrigá-los (2018). O Globo, 9 maio. Disponível em: https://oglobo.globo.com/mundo/com-mais-de-100-mil-moradoresde-rua-california-nao-encontra-onde-abriga-los-22665406?utm_source=Twitter\&utm_ medium=Social\&utm_campaign=O\%20Globo. Acesso em: maio 2018.

CUNNINGHAM, D. (2010). O conceito de metrópole: filosofia e forma urbana. Periferia: educação, cultura e comunicação, v. 2, n. 2. Disponível em: http://www.e-publicacoes.uerj.br/index.php/ periferia/article/view/3461/2377). Acesso em: abr 2018.

DASGUPTA, R. (2018). The demise of the nation state. The Guardian, 5 abr.. Disponível em: https:// www.theguardian.com/news/2018/apr/05/demise-of-the-nation-state-rana-dasgupta. Acesso em: maio 2018.

"DISCHARGED TO THE STREETS": one homeless man's struggle in freezing London (2018). The Guardian, 2 mar. Disponível em: https://www.theguardian.com/society/2018/mar/02/discharged-to-thestreets-homeless-mans-struggle-freezing-london. Acesso em: maio 2018.

EM 10 ANOS, número de moradores de rua cresceu 50\% em Paris (2017). Estadão, 3 dez. Disponível em: http://internacional.estadao.com.br/noticias/geral,em-10-anos-numero-de-moradores-derua-cresceu-50-em-paris,70002105512. Acesso em: maio 2018.

EMERGING cities set to transform league table of world's wealthiest by 2025 (2009). The Guardian, 8 nov. Disponível em: https://www.theguardian.com/business/ 2009/nov/08/emerging-citiesleague-table. Acesso em: abr 2018.

FAVELAS EM PARIS, uma cicatriz na cidade-luz (2017). El País, 27 nov. Disponível em: https://brasil. elpais.com/brasil/2017/11/25/internacional/1511631226_017741.html. Acesso em: maio 2018.

GRAHAM, S. (2012). El nuevo urbanismo militar. Antropología: Revista Interdisciplinaria del INAH, n. 94, pp. 6-18.

GUIMARÃES, N. A. (2006). Trabalho em transição: uma comparação entre São Paulo, Paris e Tóquio. Novos Estudos CEBRAP, n. 76, pp. 159-177.

HARVEY, D (2014). Cidades rebeldes: do direito à cidade à revolução urbana. São Paulo, Martins Fontes.

KURZ, R. (2004). Com todo vapor ao colapso. Juiz de Fora, Pazulin.

LEWIS, M. (2011). Bumerangue: uma viagem pela economia do novo Terceiro Mundo. Rio de Janeiro, Sextante. 
MASSEY, D. (2008). Ciudad Mundial. Caracas, El perro y la rana.

MÉSZÁROS, I. (2002). Para além do capital. São Paulo, Boitempo e Campinas, Editora da Unicamp.

NA GRANDE SP a pobreza extrema cresce 35\% em um ano (2018). Valor Econômico, 25 abr. Disponível em: http://www.valor.com.br/brasil/5480737/na-grande-sp-pobreza-extrema-cresce-35-emum-ano. Acesso em: maio 2018.

NÚMERO DE moradores de rua dispara na capital da miséria dos Estados Unidos (2017). El País, 30 dez. Disponível em: https://brasil.elpais.com/brasil/2017/12/30/internacional/1514632186 _267085.html. Acesso em: maio 2018.

NUNOMURA, E. (2008). Mumbai. Estado de São Paulo, 3 ago. Disponível em: http://www. eduardonunomura.com.br/2008/08/04/mumbai/. Acesso em: abr 2018.

OFFE, C. (1989). Trabalho e sociedade. Problemas para o futuro da "sociedade do trabalho", v. I-A crise. Rio de Janeiro, Tempo Brasileiro.

ONU (2010). Estado das Cidades do Mundo 2010/2011: unindo o urbano dividido. Disponível em: http://www.ipea.gov.br/agencia/images/stories/PDFs/100408_cidadesdomundo_portugues. pdf. Acesso em: dez 2010.

OXFORD ECONOMICS (2018). The Oxford Economics Global Cities 2030 (Executive Summary). Londres, Oxford Economics,. Disponível em: https://www.oxfordeconomics.com/Media/Default/landingpages/cities/OE-cities-summary.pdf. Acesso em: abr 2018.

PERROUX, F. (1975). "O conceito de polo de crescimento". In: FAISSOL, S. (org.). Urbanização e regionalização. Rio de Janeiro, IBGE.

PRICEWATERHOUSECOOPERS (2009). UK Economic Outlook. Londres, PricewaterhouseCoopers. Disponível em: http://pwc.blogs.com/files/pwc-uk-economic-outlook-nov-09.pdf. Acesso em: abr 2018.

ROTHKOPF, D. (2008). Superclasse. A elite que influencia a vida de milhões de pessoas ao redor do mundo. Rio de Janeiro, Agir.

SANTOS, M. (1979). O espaço dividido: os dois circuitos da economia urbana nos países subdesenvolvidos. Rio de Janeiro, Francisco Alves.

SASSEN, S. (2010). Sociologia da globalização. Porto Alegre, Artmed.

SMITH, N. (2001). Nuevo globalismo, nuevo urbanismo. Documents d'Anàlisi Geogràfica, n. 38, pp. 15-32.

TAYLOR, P. J. (2008). Urbanization in Global Perspective. GaWC Research Bulletin, 463. Disponível em: http://www.lboro.ac.uk/gawc/rb/rb463.html. Acesso em: abr 2018.

Texto recebido em 29/maio/2018

Texto aprovado em 13/ago/2018 